\title{
Aspects of Television Temporality
}

\author{
By Andrzej Gwóźdź
}

Fall 1999 Issue of KINEMA

ON SOME ASPECTS OF TELEVISION TEMPORALITY

If there is a film that makes the way of existence of its images the object of its discourse, then Cinema Paradiso (Nuovo Cinema Paradiso, by Giuseppe Tornatore, France/Italy, 1989) undoubtedly is that film. It is just here that in an almost demonstrative way the duality of a film iconosphere is shown: a pictorial passage on a film reel on the one hand, and immateriality of die luminous screen phantom on the other, a "film-reel" and a "film-projection." (1) It is here that the cinema shows its ontology as a mechanism of difference between materiality of a fundamental cinematographic apparatus and immateriality of a cinematic mechanism that actually results in the source of the cinema. If we were to look for a similar justification for the ontology of television, we would surely have to locate it within the "time of expression," that is, temporality immanent to a television image on which the "time of contents" (2) of a programme structure of television is founded. Since theoreticians of the media agree that it is just time that is "the major category of television," that "time is television's basis, its principle of strutcturation, as well as its persistent reference"(3); that "the attitude towards television should be basically derived from temporality" (4); that, finally, "the essence of the [television] screen is [...] its permanent readiness to experience time. ${ }^{(5)}$ "

No matter what stratification of the time of television (television time) is suggested by particular writers, they usually agree on the fundamental ontological premise of television temporality. For a television "videogram" - as Wolfgang Preikschat ${ }^{(6)}$ calls an electronic image - does not exist (precisely as an image) either before projection, or following it; it is not - as a screen chiaroscuro - animation of ready, "held on the alert" photographic images (frames), but it results from scanning on the surface of a kinescope that erases each previous recording (photogram) for the benefit of the omnipotence of movement, that is, of time as such.

While in film each frame is actually a static image, the television image is continually moving, very much in the manner of the Bergsonian durée - Herbert Zettl says - The scanning beam is constantly trying to complete an always incomplete image. Even if the image on the screen seems at rest, it is structurally in motion. Each television frame is always in a state of becoming [emphasis mine-A.G.] While the film frame is a concrete record of the past, the television frame (when live) is a reflection of the living, constantly changing present. $^{(7)}$

Thus Zettl's ontology identifies the fundamental temporal premise Of television that is a "productive" nature of its images, but it reduces the process to just one representational modality: a live television. But - to remain within the framework Of television picturing and, respectively, of the "time of expression" as immanent temporality of the medium - ontology of an image may not be identified with ontological determinations of the promedial world, nor can it be reduced to them.

For in television each image is a live image. A television screen is a surface of projection of a celluloid cinema film (today as a rule re-recorded on a magnetic tape), a theatrical performance played from a film reel (telerecording), a live broadcast of a sports event, of a rock concert "delayed in time" for a couple of hours or, finally, a teletext - all that always happens in "real time, ${ }^{(8)}$ " that is, in the moment which is the time of the production of an image. Being in contact with immaterial videograms that possess neither their "before" nor their "after," but always their - "here and now" only-with images produced in a visible object (a television set, a monitor) - we arc constantly participants in a "spectacle of real time." As Lorenz Engell justly remarked, "[...] an electronic image is built analogously to time rather than to space; for its essence arc "interspaces" between points $\mathrm{hl}$ an image that require to be fulfilled with the help of imagination. ${ }^{(9)}$ "

Thus electronic images - from television, computer, laparoscope, to electronic mail - does not primarily image representations but time in its dynamic form of "time-image" that is permanently becoming, in an "incomplete" state, from which as a state of temporariness we are to reconstruct an imperfect "grammar" of a luminous surface of a kinescope. 
That structural matrix of "real time" of television picturing is always involved in temporality of the programme flow of television, in television as a programme, though. And television constantly reminds of its broadcast time, staging its passage in different ways. For broadcast time is measured not only with its programmes (serving with that respect the function of a "social generator of time"), ${ }^{(10)}$ besides, time itself is made an object of a message, providing broadcasts with a character of a permanent. and ubiquitous speaking clock (let us just think of total "monitoring" of the day due to permanent demonstration of television clocks rather than non-television clocks). Television seems thereby to compensate for the lack of an ontological foundation of images with the "absolute presentness of a medial event" (11) that guarantees at the same time simultaneity of television and non-television time.

Not an insignificant role is played with respect to that by co-ordinates of a television broadcast. For a monitor image encompasses the chronotopology of the place in which a television set is located and the light of a television set annexes that chronotopology within the image broadcast. Thereby everything that is within its reach determines the contents of a videogram as much as the contents of images themselves. That means that the meaning of a videogram is the whole space-time lightened up by a kinescope image. The sign (symbolic) and the real (non-symbolic) form common space-time of a broadcast - a television sign has its meaning as the environment that encompasses luminosity of the screen. ${ }^{(12)}$ That property of a television instrument decidedly separates television from cinema, the latter basing its imaginations on the transgression of the boundary between real and symbolic space, on the constitution of the space of perception as a symbolic form.

But what is also at stake arc more trivial arguments connected with our experience of television that has originated, incidentally, in a live television and that still uses it in tile function of a fundamental representational mechanism (as opposed to the cinema that by its definition can never be live). We used lo see live television as television par excellence and to transfer that experience to other forms of it, treating the majority of images as live images. Perhaps we even used to evaluate it higher than other images, which might be testified by, for instance -- redundant from the point of view of representational strategies -- providing some programmes with an additional "live" caption as an unequivocally positive temporal and genre determination.

It may be here that lies the "third meaning" of a television image (so brilliantly recognized for the cinema by Roland Barthes in stills of Sergei Eisenstein's films ${ }^{(13)}$ ) - a result of a teletopological and teletemporal unity itl which the order of seeing is made equal to the order of things around the apparatus, "bending"(14) the broadcast time to the present moment. It was Vivian Sobchack who based her opposition of the "absolute present" [absolute "Gegenwärtigkeit"] of electronic images and "present presence" ["Gegenwärtigkeit" in der Gegenwart] of film images on the difference between television and cinema instruments, saying that in electronics "the system 'past-present-future' is already pointless."(15) And Neil Postman simply says: "[...] Television is a speed-of-light medium, a present-centred medium. Its grammar, so to say, permits no access to the past. Everything presented in moving pictures is experienced as happening 'now' [...]."(16)

Obviously, the most advanced "grammar" of staging the "absolute present" of television is presented by a live transmission. But it is just a paradigmatic case of electronic generating of images in general, a visible citation of' the technology of production of a videogram. This mechanism of presenting the reality that maintains the unity of the "time of expression" ("real time") and the time of reception is here merely simultaneously repeated - also "live" - in the very way of production of a videogram. The product (image) and the process of its production simulate each other, showing the Baudrillardian "connection of the same to the same."(17)

And although a live broadcast is the only example of the "absolute presentness of a rnedial event" of simultaneity of a non-medial event and of its reception, i.e. full synchronization of images and perceptions, ${ }^{(18)}$ the presence and immediateness imagined are not threatened even if the "time of expression" is disturbed due to modulations proper to the time of statement. Jane Feuer has described the mechanism in question on the basis of the example of sports reports.

"Whole" events are segmented and fragmented through excessive commentary used for narrativization: the figure-skating pairs competition becomes the saga of the young couple's unrealized dream. We cut back and forth between discrete events. Boring events such as cross country skiing ("boring" being the equivalent of "not designed for television") are enlivened through time-lapse editing. Instant replays and slow motion 
endlessly analyze the unique and spontaneous events in the name of the broadcast. The ideology of liveness [emphasis A.G.] overrides all of this. Network television never truly exploits its capacity for instantaneous and unmediated transmission. Only the ideological connotations of live television [emphasis A.G.] are exploited in order to overcome contradictions between flow and fragmentation in television practice. ${ }^{(19)}$

Such a temporal separation allows to manipulate the effect of the "absolute present" (of a medial and nonmedial event) in such a way that it assumes characteristics of the "virtual present" ${ }^{20)}$ noticed by Susanne K. Langer in film. Thereby e.g. the control of a terrorist attack from a television terminal would be ineffective as even a delay of a couple of seconds in a broadcast (actually even playing from a video recording) might baffle the whole action. ${ }^{(21)} \mathrm{Or}-$ as is the case in the film The Real McCoy (directed by R. Mulcahy, USA, 1993) - it makes it possible to "falsify" a live broadcast from television surveillance in a bank, to replace it with a video recording which nevertheless maintains the authority of directness of a live image.

It is paradoxical that authentication brought about by live television as an institution of presence and directness does not have to have much to do with truth. "The impression of presence" (and thereby the ideology of a witness) are often unmasked as an effect of submitting the reality itself that allows far-reaching use of perceptions in the function of images when e.g. there is a clash resulting from overlapping of the representational time of a broadcast and the time of broadcast (for instance, often present in sports broadcasts): "Live' is an electronic surrogate of mechanical relations between a cause and an effect ${ }^{(22)}$ - says Preikschat, seeing in a live transmission a substitute for causal relations between an image and an object.

That is the case due to, among other things, an inclination proper to television to mark the "zero time" (that eliminates the difference between an event and its broadcast), to submit it to various transformations in the "laboratory time"(23) that refers to temporal modalities resulting from stylistic endeavours. But that "made" time maintains the quality of "another now" as none of tricks employed here - replay, slow motion, fast motion, phasing, fractalization of motion etc. - is an interference in direct experience of time, since the Heidegger's "time of the world" (Natur- und Weltzeit), ${ }^{(24)}$ constantly present e.g. in a commentary from the off side, natural sounds from a sports field, in a word - respecting the same temporal modal framework, is not suspended. On the contrary, what is at stake here is the immediate authentication of what is shown in a teleiconic gaze, a kind of incrustation of the "absolute present" with a retarded perception that is from the domain of the same images, though, rather than the substitution of one temporal structure with another.

Thereby "there appears a microscopic perception of time that leads to an evaluation of a different kind that seems to us to be more objective, but finally is of an imaginative nature [emphasis A.G.], that is to say, consists in images." $(25)$

The same can be said, for instance, of close-circuit television often present in supermarkets, offering a live broadcast from a production part of a store. In one of them, owing to a monitor located above freezers with bacon and steaks, there occurs not only the extension of an adjoining meat factory to a store (and thereby the secret of meat production is revealed), but that is a "permanent pan-cinema," as Paul Virilio would say, ${ }^{(26)}$ that totally submits its broadcast to the exhilaration of presence. For those images neither represent, nor simulate anything, they sanction in an act of an ontological interaction with objects of reference the clash of the same with the same. Rene Berger who identified a similar type of "extension" of our senses behind the represented in a broadcast of the landing on the Moon of the Apollo XVI mission, calls it "sensorial temporality." In that case we are no longer merely viewers, but owing to a tele-gaze of a screen, we become tele-present. "The time in which an event happens is felt as more authentic than the very representation of it that requires a form recorded on a carrier - the reading of which is always reduced to an indirect and discontinuous operation" (27) (which according to the writer, incidentally, is one of the fundamental conditions of reviving mythical participation that occurs owing to a live television broadcast).

But the "indirectness and discontinuity" of reception resulting - according to Berger - from the replacement of broadcast with representation (that is, from fictionalization of the "absolute present") no longer holds in the case of a videotape. As a magnetic carrier of television images maintains the property of a live broadcast even if representation seems to be dominating. Let us take a closer look at an ontological justification of such a position.

Since a videotape is connected with an image generated on a monitor (no other image is available) only 
by the relation of production rather than by any other relation of an image nature (a tape does not have any images, but only immaterial bits of information for a video-recorder-television set installation), it does not have at its disposal any analogue of the reality between itself and its screen image. So an information matrix of magnetic recording has neither an iconic code, nor any other system of visible representation of the world presented. What is at stake is in fact an "image without an image [...] a zero image," (28) never and nowhere existing -- apart from a monitor -- as images, that is, as iconic representations of the reality. Rolf Freier rightly says in that context that "although electronic recording of an image has at its disposal a referential code that guarantees the reference of particular image signals [to the reality], but neither at the source of that reference there is simple reversibility of that function, nor is it perceptible by senses: an electronic image is non-referential." ${ }^{(29)}$

So we deal here with disappearance of a classical model of representation seen as image, materially-founded mimesis. Between promedial reality and videograms there is an installation that releases iconicity from its dematerialized recording and $\mathrm{hl}$ fact substitutes previously absent relation of representation only on the level of production of an image - within a medium. That means that an image from an electronic recording does not set in motion "medial codes" (30) additional with respect to a live broadcast, but they initiate an identical correlation between percepting and recognizing images, although it is usually more clearly marked by the "laboratory time" (familiar also to, as we have seen, a live broadcast).

Consequently, a videotape is perceptively identical with a live transmission, initiating the same 'live" connotational paradigm. Therefore it is necessary to provide archival video materials with an appropriate commentary (e.g. the remark "Archives"), owing to which a viewer will know that the material he is currently watching has been recorded in the past. Perhaps, as Doane remarked, "[that] the appellation itself reduces the credibility of the story," (31) but that also allows to avoid the identification of "old stuffs" with directness, and, as a result, to avoid evident interpretational mistakes, inadmissible especially in informational programmes that particularly have to rely on the use of archival tapes.

It has to be remembered, though, that a viewer has at his disposal various signs of temporal location allowing him to good choices of proper temporal modalities -- from fashion, stylistic codes of television messages, to verba1 signification -- although the possibility of making a mistake due to unfortunate "temporalization" of a text are not thereby totally excluded. That may result also from the fact that proper semantics of time is activated only on the 1evel of a programme flow - television as a discourse - but not already within perceptions or merely images. For they are invariably submitted to the effect of presence and immediacy of a live transmission. That especially can be seen in the case of a collage of a live transmission, a material recorded on a magnetic tape and, for instance, a cinema (celluloid) film or a material shown from the socalled telerecording (i.e. a film recording of a television programme, practised in the era preceding common application of a magnetic tape).

While the two temporal modalities in question - a live transmission and videofilm - bring about the same effect of the "absolute presence" (of both an image and a representation), film and telerecording value the "present presence" of what is past, that is, absent, being recorded in the form of a luminous trace of the reality. And as it has been recorded, it has in fact never been present, requiring operations that could have happened only in the past, only in the "time of a physical manipulation of a carrier"(32) needed to produce that whole (developing, postproduction, especially editing, making copies) and then to distribute it. Television reproduces traces of those processes saved in a material substratum as a citation of the "time of physical wear" (33) (a worn out, scratched copy, bursting endings of acts, deformations of a soundtrack - especially in archival films), the time that it is not subject to, remaining invariantly a sign of imagined presence and immediacy.

Thereby the effect of television activates claims to validity that come under the paradigm of non-fictional truth (the true but also, at the same time, the actual; the real, but, at the same time, also present here and now). The effect of the cinema seems in turn to be supported by claims to validity proper to fictional truthfulness (what could have happened, but has always already happened; the true, but not necessarily actually real). From the two ontological foundations, celluloid means maintaining the past (according to Langer), while a magnetic recording is an indication of the actual ("the absolute present"). Obviously, the point is not to identify some metaphysics of a carricr but to recognize fundamental perceptional and 
interpretational standards that influence the semantics of a medium.

That is, incidentally, the difference between two civilizations of images -- between a chemical and an electronic one -- which coexist in a contemporary iconosphere not only on the basis of competitive temporal modalities, but, more generally, of representational modalities. ${ }^{(34)}$ Owing to that there is a clash between various temporalities, mutual "playing off" of different "message codes" against one another.

Although Calvin Pryluck maintains that "image communication is used more-or-less as a transmission channel for any environmental object or event. Only in limited circumstances can there be transmission without coding. The camera is a simple transmission channel when is used as a technical recording device, for instance, micro-photography transmission of a motion picture on a television film-chain,"(35) it is precisely owing to the intervention of "message codes" that there occurs semiotization of the difference that results from the presence of one medium within the other, from representation of one type of message coding by another type of it. The point is that meanings begin to appear from the very interference of carriers and that occurs somehow below the threshold of intentionality of meanings, in an interface between substantial representations of the media.

That would mean that the decision whether a given material will be recorded on a film (photosensitive) reel or on a magnetic tape is in fact the decision influencing the semantics of message. Indeed, there is enough evidence to confirm that observation. Wim Wenders, for instance, recalls in 1991 the production of his Nick's Film Lightning Over Water (West Germany 1979/1980):

It was much earlier, almost ten years ago, that I already used the technique of video. It was in "Lightning over Water" with Nicholas Ray. I remember how inconvenient it was, how bad the picture was, how difficult it was to work and how in that film with Nicholas Ray I considered it to be a tumour in the film [emphasis A.G.], for it was just the aim we used the technique for it was a film about illness, and video inside appeam3 to me just like an illness [emphasis A.G.]. ${ }^{(36)}$

What is well-known is the case of decision makers from ABC Networks who decided that a "film" about the US Olympic hockey team had to be made, that the videotape look had too much "immediacy," it felt to them too much like a live sports events rather than a movie. They preferred a degraded image which seemed more comparable to a documentary film than a live telecast."(37)

Obviously, such temporal distinctions function because they constitute the system of differences that makes the "clash" between the media gain a semantic dimension.

It seems that it is in the interface between various substantial modalities that represent different medial forms and, as we have seen, signify different temporal modalities, that there is one of the fundamental mechanisms of intermediality of television and cinema. ${ }^{(38)}$

(Previously published in: Eugeniusz Wilk ed., Methodology Culture Audiovisuality, Warsaw/Katowice: Slask Instytut Kultury, 1998.)

\section{Notes}

1. T. Kuntzel, "Le Défilement: A View in Close Up" (in:) T. Hak Kyng Cha (ed.), Cinematographic Apparatus. Selected Writings, New York 1981, p. 239.

2. Umberto Eco, "Il tempo dell'arte" (in:) idem, Sugli specchi e altri saggi, Milano 1985, pp. 115-124.

3. M. A. Doane, "Information, Crisis, Catastrophe" (in:) P Mellencamp (ed.), Logics of Television. Essays in Cultural Criticism, London 1992 (2nd edition), p. 222.

4. L. Engell, Vom Widerspruch zur Langeweile. Logische und temporale Begründungen des Fernsehens, Frankfurt am Main-Bern-New York-Paris, 1989, p. 170.

5. R. Berger, "Restructuration du mythe" (in:) idem, La télé-fission. Alerte à la télévision, Paris 1976, p. 


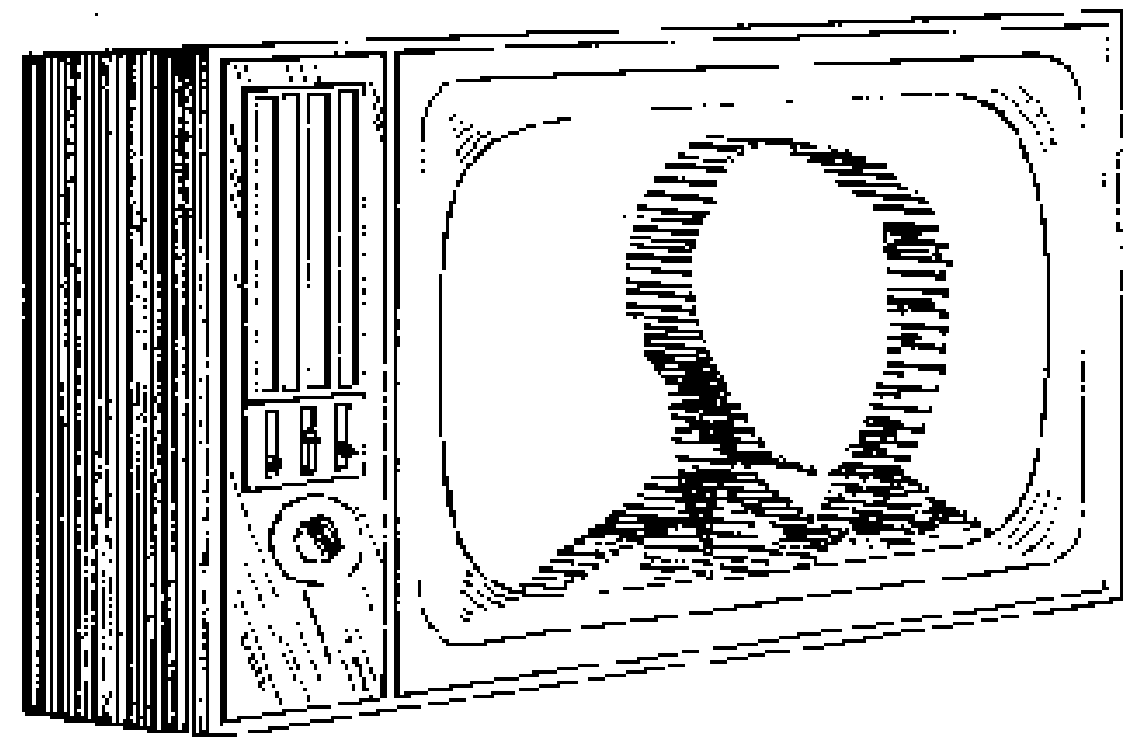

Figure 1:

57.

6. See: W Preikschat, Video: Die Poesie der neuen Medien, Weinheim und Basel 1987, p. 87ff.

7. H. Zettl, "The Rare Case of Television Aesthetics," Journal of the University Film Association 1978, vol. 2 (Spring) p. 3ff.

8. "Real time" (temps réel, Echtzeit) is a concept from the domain of computer technology and means total overlapping of the process of analysis, calculations and computer control of the very process: approximately, it is a "rapid time" that suppresses the distinction between the effect (here: an image) and the process leading to its production (here: scanning of the screen surface with cathode rays).

9. L. Engell, Vom Widerspruch zur Langeweile..., p. 138.

10. I. Neverla, Fernseh-Zeit. Zuschauer zwischen Zeiltkalkül und Zeitvertreib. Eine Untersuchung zur Fernsehnutzung, München, 1992, p. 58ff.

11. L. Engell, Vom Widerspruch zur Langeweile..., p. 99. What is at stake is a "medial event" as an image event that takes place on the surface of a screen (monitor).

12. See P. Virilio, 'La lumière indirecte," Communications 1988, vol. 48, pp. 45-52.

13. See: R. Barthes, "The Third Meaning. Research Notes on some Eisenstein Stills" in: idem, Image-MusicText, New York 1977, p. 52-68.

14. J. Paech, "Das Fernsehen als symbolische Form," in J. Paech, A. Ziemer (eds.), Digitales Fernsehen eine neue Medienwelt? Interdisziplinäre Tagung an der Universität Konstanz 1993, Mainz 1994, p. 85.

15. V. Sobchack, "The Scene of the Screen." Beitrag zu einer Phänomenologie der" Gegenwärtigkeit "im Film und in den elektronischen Medien", in H. U. Gumbrecht, K.L. Pfeiffer (Hrsg), Materialität der Kommunikation, Frankfurt am Main 1988, p. 423ff.

16. Neil Postman, Amusing Ourselves to Death. Public Discourse in the Age of Show Business, London 1986, p. 136.

17. J. Baudrillard, "Videowelt und fraktales Subjekt" (in:) Ars Electronica (ed.) Philosophien der neuen Technologie, Berlin 1989, p. 116ff.

18. On the subject of the distinction between perceptions and images, see L Engell, Vom Widerspruch zur 
Langeweile..., p. $192 \mathrm{ff}$.

19. J. Feuer, "The concept of Live Television: Ontology as Ideology" (in:) E. Kaplan (ed.) Regarding Television, Frederick, MD. 1983, p. 16.

20. S. K. Langer, "A Note on the Film" (in:) idem, Feeling and Form. A Theory of Art Developed from "Philosophy in a New Key", London 1963, pp. 250-252.

21. See: M. Sjöwall, P. Wahoo, Die Terroristen, Reinbek 1977.

22. W. Preikschat, Video..., op. cit., p. 59.

23. See: H. Nowotny, Eigenzeit. Entstehung und Strukturierung eines Zeitgefühls, Frankfurt am Main 1989, pp. 94-95.

24. M. Heidegger, Der Begriff der Zeit. Vortrag vor der Marburger Theologengesellschaft, Juli 1924. Herausgegeben und mit einem Nachwort versehen von H. Tietjen, Tübingen 1989, p. 7.

25. W. Preikschat, Video..., op. cit. pp. 59-60.

26. See: P. Virilio, Das öffentliche Bild, Bern 1987.

27. R. Berger, "Restructuration du mythe...", of. cit. p. 57.

28. P. Bonitzer, "L'image invisible" in R. Bellour, C. David. Ch Van Assche (eds.), Passages de l'image. Catalogue de l'exposition, Paris 1990, p.12.

29. R. Freier, Der eingeschränkte Blick und die Fenster zur Welt. Zur politischen Ästhetik visueller Medien, Marburg 1984, pp. 129-130. So the archives of videotapes are not - as opposed to a film library - places to store images but to store their carriers only, like a particular videorecording is "memory without recording" as it is deprived of any image representations (see L. Engell, Vom Widerspruch..., op. cit., p. 231).

30. See: Umberto Eco, La struttura assente, Milano 1985, p. 146 (3rd edition).

31. M. A. Doane, "Information, Crisis, Catastrophe...", op. cit., p. 226.

32. Eco, Il tempo, op. cit., p. 120.

33. Ibid., p. 116.

34. See: Guido Aristarco, "Il cinema. Dalla chimica ai processi elettronici," Cinema nuovo 1983, Aprile.

35. C. Pryluck, Sources of Meaning in Motion Pictures and Television, New York 1976, p. 74.

36. Wim Wenders, "Die Wahrheit der Bilder. Zwei Gespräche mit Peter W. Jansen" (in:) idem, The Act of Seeing. Texte und Gespräche, Frankfurt/Main 1992, p. 70.

37. See: R. Patterson, "Film Tape or Video?," American Cinematographer 1982 (March), p. 226

38. See: A. Gwóźdź, "Das Kinematographische tele-vis(ion)iert" in J. Paech (Hrsg.), Film, Fernsehen, Video und die Künste. Strategien der Intermedialität, Stuttgart-Weimar 1994, pp. 179-189, and idem, "On Some Aspects of Intermedial Film Transfer" in W. Nöth (ed.), Semiotics of the Media: State of the Art, Projects, and Perspectives, The Hague 1997, pp. 337-345.

\section{Author Information}

Andrzej GWÓŹDŹ is Professor at the Silesian University in Katowice (Poland). His professional interest focuses on film theory and problems of electronic media. A noted film theoretician in his country, Prof. Gwóźdź has held visiting posts at academic institutions in Germany, Austria and Holland. He is the author of nine books on film theory, including the groundbreaking anthology Filmtheorie in Polen (1992). 